\title{
Editorial
}

www.anatomy.org.tr

Published online: August 26, 2009

doi:10.2399/ana.09.029

\section{The importance of a journal to a scientific association}

\author{
Stephen W. Carmichael ${ }^{1}$, Salih Murat Akkın², Hakan Hamdi Çelik ${ }^{3}$ \\ ${ }^{1}$ Editor-in-Chief, Clinical Anatomy; Department of Anatomy, Mayo Clinic, Rochester, MN, USA \\ ${ }^{2}$ Editor-in-Chief, Anatomy; Department of Anatomy, Cerrahpaşa Medical Faculty, Istanbul University, Istanbul, Turkey \\ ${ }^{3}$ Editor-in-Chief, Anatomy; Department of Anatomy, Faculty of Medicine, Hacettepe University, Ankara, Turkey \\ Anatomy 2009; 3: 1-2, @ 2009 TSACA
}

Scientific associations are collections of scientists with specific interests in common. In the case of the Turkish Society of Anatomy and Clinical Anatomy (TSACA), this is a group of (mostly) Turkish anatomists with common interests in human anatomy and medical education. They typically meet on an annual schedule when they can gather in one place and discuss their common interests in detail. This year (2009) is special because the TSACA is hosting the biannual meeting of the European Association of Clinical Anatomists so the gathering will be from a much larger geographical area (practically the entire world!) and many more anatomists will be involved.

Whereas regular gatherings of this type are enjoyable and intellectually stimulating, they only occupy a few days out of the year. What about the other 360 or more days in the year? Undoubtedly there are continuing collaborations and discussions among colleagues that were initiated at the annual meeting, but the sharing of ideas and information is clearly diminished.

How can this void be filled? As the reader can tell from the title of this article, one possible answer is for the scientific association to have a journal that all members (as well as anatomists from outside the association) can contribute articles, and thereby ideas and information can be shared with others. In this age of the internet, information can be instantaneously distributed to wherever an internet connection can be obtained. We maintain that a journal that reflects the interests of a scientific association can provide a platform for sharing ideas and information 24 hours a day, 7 days a week, with worldwide distribution.

What responsibility does this place on the members of the scientific association? Importantly, this obligates the members to conduct studies with sound scientific methods and to submit a description of these studies (manuscripts) to be considered for publication in the association's journal. This is when the peer-review process comes into the picture.

Another obligation of the members is the serve as peer reviewers. That is, to carefully read manuscripts and offer constructive comments as to how the manuscripts could be improved. If the manuscript does not provide important information, the peer reviewer needs to point this out. In this case the manuscript may not warrant publication. However, if the manuscript does provide worthwhile information, the peer review process almost always results in a better manuscript. This is a benefit for everyone who reads the published article.

On the negative side, it is very difficult to launch a new journal at the present time. Even before the current global economy took a downturn in 2008, the future of journal publications was unclear. We must appreciate that commercial publishers need to show a profit in order to stay in business. The traditional business model 
has essentially been to provide members of an association with a journal subscription at the price it costs the publisher to print and distribute the journal. The publisher does not make a profit by providing this benefit to association members. However, subscriptions to libraries (in this case, medical libraries) are set at a higher level that allows the publisher to stay in business. But budgets of medical libraries have been declining for many years and librarians have had to be more selective in choosing which journals they should purchase for their libraries. This has been further complicated by the introduction of on line publishing. It is much less expensive to put information on line than to print and distribute journals. At some time in the future, hard copies of journals will disappear and all publication will be on line. Nobody knows when this will happen, but it is inevitable.
Another possibility that is being discussed is to alter the "business model" of publishing scientific journals. Rather than have the financial burden on medical libraries, the burden could be shifted elsewhere. One suggestion is to shift it to authors by requiring them to pay a substantial fee to submit a manuscript. Whereas this model has some merit in parts of the world where authors are well funded, it simply won't work in parts of the world where authors clearly cannot afford such a fee to support publishers, even if the journal is on line.

In conclusion, a journal sponsored by a scientific association (or a group of like-minded associations) is an important undertaking that promotes the science year round and world wide. However, those involved in this important enterprise need to be aware of the financial realities of journal publication. 